\title{
Interpreting definiteness in a second language without articles: The case of L2 Russian
}

Second Language Research $0(0) 1-32$

(C) The Author(s) 2013

Reprints and permissions: sagepub.co.uk/journalsPermissions.nav DOI: I0.1 I77/02676583|3509647 sir.sagepub.com @SAGE

\section{Jacee Cho}

University of Wisconsin-Madison, USA

\section{Roumyana Slabakova}

University of lowa, USA; University of Southampton, UK

\begin{abstract}
This article investigates the second language (L2) acquisition of two expressions of the semantic feature [definite] in Russian, a language without articles, by English and Korean native speakers. Within the Feature Reassembly approach (Lardiere, 2009), Slabakova (2009) has argued that reassembling features that are represented overtly in the first language (LI) and mapping them onto those that are encoded indirectly, or covertly, in the L2 will present a greater difficulty than reassembling features in the opposite learning direction. An idealized scale of predictions of difficulty is proposed based on the overt or covert character of the feature encoding and the ease/difficulty of noticing the feature expression. A total of 158 participants (56 native Russian, 49 English learners and 53 Korean learners of Russian) evaluated the acceptability of test sentences in context. Findings demonstrate that acquiring the expression of a feature that is encoded contextually in the $L 2$ is challenging for learners, while an overt expression of a feature presents less difficulty. On the basis of the learners' developmental patterns observed in the study, we argue that overt and covert expression of semantic features, feature reassembly, and indirect encoding appear to be significant factors in L2 grammatical feature acquisition.
\end{abstract}

\section{Keywords}

definiteness, direct and indirect feature encoding, English-Russian interlanguage, feature reassembly, Korean-Russian interlanguage, L2 Russian, semantic features

\footnotetext{
Corresponding author:

Jacee Cho, Department of English, University of Wisconsin-Madison, 600 North Park Street, H.C. White Hall, Madison, WI 53706, USA.

Email: jcho62@wisc.edu
} 


\section{Introduction}

Recent years have seen a lot of interest in investigating syntax-semantics mismatches in second language acquisition (Dekydtspotter and Sprouse, 2001; Dekydtspotter et al., 1997; Gabriele, 2005; Gürel, 2006; Hawkins and Hattori, 2006; Marsden, 2009; Montrul and Slabakova, 2003; Slabakova, 2003; for an extensive discussion and review of studies on syntax-semantics mismatches, see Slabakova, 2008). A syntax-semantics mismatch refers to the situation when some universal meaning (e.g. plurality, ongoing action, past event, definiteness, politeness) finds expression in one way in the native language and in another way in the target language. Although learners arguably have access to the whole arsenal of universal conceptual meanings (Jackendoff, 2002), they have to learn how to express the meaning in the new language. Very often, a new expression of a meaning appears in different conditioning environments (to be elaborated on below), which makes the acquisition task much harder. Acknowledging this significant acquisition challenge, Lardiere $(2008,2009)$ proposes the Feature Reassembly Hypothesis. The hypothesis views second language (L2) acquisition as involving the assembly or reassembly of the formal feature matrices of functional categories and mapping them onto their new morphological exponents. The process conceivably goes through two steps, which may be of differential difficulty and consequently may take different amounts of time to accomplish. The first step is based on perceived similarities between the functional meanings of the target morpholexical items and the first language (L1) morpholexical items. ${ }^{1}$ These similarities lead to initial mapping of the complete feature set of the L1 item onto the target item. In principle, there may be one-to-one, many-to-one, one-to-many, or many-to-many possible mappings. Once some initial mapping is established, the next step involves 'feature reassembly': features can be added or deleted, progressively adjusting the target feature set to the evidence for meaning and usage coming from the input. Such feature reassembly may be slow to occur or may not occur at all if the relevant evidence for the formal or semantic feature is rare or contradictory in the linguistic input. Finally, the native language can either aid or obstruct feature reassembly.

While the mechanism described above is well suited to the acquisition of formal syntactic features, say [case] or [wh], the learning situation for semantic features may be somewhat different. As a systematic difference between languages, various aspects of meaning are lexically marked in some languages while they appear to be unmarked in other languages. Number, evidentiality and focus have been discussed in this respect (e.g. for number, see Chierchia, 1998; for evidentiality, see Lazard, 2001). Since the relevant interpretations can still be successfully communicated by speakers, regardless of whether they are lexicalized or not, the question that arises in languages that fail to lexicalize a given meaning is where the 'extra' meaning comes from. One possibility is to propose 'semantic parameters' (e.g. Chierchia's 1998 Nominal Mapping Parameter), where the same syntactic form (NP, Det) corresponds to different semantic types in the different languages. Such an approach to dealing with parametric variation presupposes a separate module mediating between syntax and the Conceptual-Intentional systems (C-I, Chomsky, 2004).

Taking a different approach to parametric variation, Ramchand and Svenonius (2008) reject the possibility that such a semantic module is necessary on economy grounds. 
They suggest that syntax/semantics representations interface with and are interpretable directly by the C-I systems. Consequently, the differences between languages can only be captured within the featural specifications of morpholexical items (most commonly, functional morphology but not only). This is a strong minimalist thesis that imposes strict architectural limits on the language faculty and, as such, it is worth pursuing until proven erroneous. The authors argue for the possibility that the C-I systems are universal, but that the mapping between syntax (what they call syn/sem, or core syntax with semantic features) and the C-I systems is non-trivial, such that the same proposition or grammatical meaning (e.g. definiteness) can be read off of different syn/sem representations (e.g. articles versus various other lexical means for expressing definiteness). The computational system of core syntax assembling syn/sem representations is also universal; however, different languages may employ different lexical items with different features to encode the same meaning. A crucial trait of this view of the grammar is underspecification (Halle and Marantz, 1993), both in lexical and morpholexical (functional) morphemes. To take an example cited in Ramchand and Svenonius (2008), compared to the explicit dual marking in Northern Sámi personal pronouns mii 'I and others' and moai 'I and one other', English we is underspecified, and can be disambiguated (if necessary) by adding lexical items (I and others versus I and one other person). By conceptual necessity, if the $\mathrm{C}$-I systems and the syn/sem representation-building mechanism are universal, then 'the syn/sem system inevitably underdetermines full contextually augmented meaning' (Ramchand and Svenonius, 2008: 222).

This view of the language architecture presents an interesting perspective to second language acquisition researchers dealing with syntax-semantics mismatches. Conceptualizing a syntax-semantics mismatch as a syn/sem representation of the same meaning that is built from different (morpho-)lexical ingredients in the two languages (or even supplied by the context), combined with Lardiere's feature-based L2 learning process, allows us to make more concrete predictions on the ease and difficulty of particular language pairings and particular learning directions (Slabakova, 2009). Let us consider definiteness as an example. Definiteness is not a simple concept: it consists of a number of semantic components such as familiarity, presupposition of existence, and uniqueness (Heim, 1991). We assume an informal definition of definiteness based on presupposition: a nominal is definite when there is a presupposition of its referent being unique in the domain of discourse, where uniqueness can be established through previous mention or world knowledge. ${ }^{2}$ This is true for singular nouns only, for plural nouns there is a presupposition of maximality, that is all members of a specified set.

Consider the situation where the first step in Lardiere's learning procedure, namely, looking for morpholexical correspondences between the L1 and the L2 items based on grammatical function and meaning similarities, may not lead to an obvious mapping. That would be the case of definiteness marking where the L1 language uses definite articles and the L2 does not. One could reasonably predict that learners who find themselves in such a situation would not assume that definiteness is not marked in the target language, but they will surmise that definiteness is signaled by some other linguistic means. However, the learning task of monitoring the input to detect the various (nonarticle) morpholexical means of marking definiteness will be quite a different process from that of the other learning direction, where definiteness is marked with articles. It is 
ultimately an empirical task to discover which direction will present more difficulty. We consider this issue in Section VII.

As an illustration of the difficulty of acquiring definiteness in languages without articles, consider the fact that only articles express definiteness through dedicated functional morphology, thus directly. Other feature expressions are then by definition indirect, and there lies the crux of acquisition difficulty. Indirect expressions of a feature have some other, primary grammatical meaning (semantic feature) to express. Take for example demonstratives, the closest functional words to definite articles. Definite expressions can be marked by demonstratives, but only through their deictic feature, call it [DEM] following Guisti (2002), which is their primary feature. It turns out that a similar situation obtains with other expressions of definiteness in languages without articles: e.g. word order, information structure, adjectival possessors, etc. All these expressions may express the feature [definite], but in addition to some other semantic feature, which is their fundamental feature, or raison d'être. Thus, definiteness is inferred only indirectly, through overlap with the other features that is by definition less than $100 \%$. Since its marking is encountered with less regularity and in less consistent input, definiteness is difficult to acquire.

In this article, we look at two (out of the many possible) ways of signaling definiteness in Russian, a language without articles. We compare the L2 acquisition of two (unrelated) definiteness-indicating constructions by English and Korean learners of Russian. The two native languages were chosen with L1 transfer in mind: English has dedicated definite and indefinite morphology (articles) while Korean does not. In the next two sections, we review recent research on the acquisition of definiteness and describe Ramchand and Svenonius's (2008) proposal on definiteness marking across languages. In Section IV we spell out our assumptions and make more general as well as some concrete predictions about acquisition of syntax-semantics mismatches. In Section $\mathrm{V}$ we present the interpretive properties under scrutiny. Section VI describes the experimental study and presents group as well as individual results. Finally, we discuss some theoretical implications of the findings and conclude that the overt and covert encoding, as well as direct and indirect expression of features should be treated as significant factors in L2 feature reassembly.

\section{Second language acquisition of definiteness}

The majority of studies on the L2 acquisition of definiteness marking look in the opposite learning direction from the one we have taken in this article: the target language is English. Early research on article acquisition (Huebner, 1983; Thomas, 1989; among many others) has established that L2 English learners, particularly those speaking a native language without articles, have persistent difficulties with articles. They often overuse the with indefinites and/or overuse $a$ with definites. A number of proposals have been made to account for these patterns of article misuse, including purely syntactic (Trenkic, 2008) and prosodic accounts (The Prosodic Transfer Hypothesis; Goad and White, 2004).

Offering a semantic explanation of article misuse, Ionin et al. (2004) proposed the Article Choice Parameter with two settings in languages that have two articles. In one 
type of language, articles are distinguished on the basis of specificity; in the other type articles are distinguished on the basis of definiteness. This linguistic situation presents specific difficulties for learners whose native language does not mark these features morphologically. Since the Article Choice Parameter is purportedly a semantic universal, L2 learners fluctuate between the two settings of the Article Choice Parameter until the input leads them to set this parameter to the appropriate value. This is known as the Fluctuation Hypothesis, and it makes very concrete predictions for the pattern of errors in L2 acquisition: learners are supposed to make errors overgeneralizing the in indefinite specific situations and $a$ in definite nonspecific situations.

Group results from Ionin et al.'s (2004) Russian learners largely support the Fluctuation Hypothesis, in that learners overused articles in precisely the predicted learning conditions. However, the individual results presented a more complex picture where a number of individual participants did not exhibit the expected pattern. In addition, their production results revealed that learners overused the with specific indefinites, but did not overuse $a$ with nonspecific definites. As Ionin et al. (2004) discuss, however, there were arguably very few contexts that allowed for nonspecific definites in the production data, making the production error patterns somewhat tentative and inconclusive. The series of studies by Ionin and colleagues has proved highly influential and has inspired a number of following studies (Garcia Mayo, 2009; Snape, 2009; Zdorenko and Paradis, 2008; among others) largely confirming the fluctuation findings. However, Trenkic (2008) takes issue with Ionin et al.'s operationalization of specificity and argues against the Fluctuation Hypothesis by proposing that L2 English learners are mis-analysing the and $a$ as adjectives.

This brief review suggests that while some adult learners of English articles from article-less languages fluctuate between marking definiteness and specificity, other groups of learners at similar proficiency levels do not fluctuate much. The Fluctuation Hypothesis is an influential current explanation for the error patterns, but there is still more to explain in the findings to date. In Section VII, we will compare our results to those of Ionin et al. (2004) in order to tentatively examine which learning direction is harder, English to Russian or Russian to English, in the marking of definiteness.

\section{The feature [definite] and its possible expressions}

As discussed in the introduction, we follow Ramchand and Svenonius (2008), who argue that all languages have the same formal syntax (syn/sem) and Conceptual-Intentional systems (Chomsky, 2004), or Conceptual Structure (Jackendoff, 2002). Thus, language variation lies only in the way languages express the universal meanings. Some languages express those meanings morphologically or syntactically, and some languages express those meanings postsyntactically through context. ${ }^{3}$ However, Ramchand and Svenonius (2008: 225) also argue against identical syn/sem (or LF) representations in all languages. They capitalize on some semantic features left underspecified by the syntax and interpreted by the C-I systems, for example tracking of referents in the discourse. Their approach forces all languages to have a DP projection so that nominals can be interpreted as arguments; however, some languages have overt morphophonological material in the D head while others have null D heads. More concretely, English has two distinct D 
Table I. Parametric variation in encoding nominal features across languages of the world.

\begin{tabular}{lllll}
\hline Meanings & Norwegian & English & Lillooet Salish & Russian \\
\hline Argumenthood & syn/sem & syn/sem & syn/sem & syn/sem \\
Definiteness & syn/sem & syn/sem & C-I & C-I \\
Specificity & syn/sem & C-I & syn/sem & C-I \\
Argument tracking & C-I & C-I & C-I & C-I
\end{tabular}

elements $(a$, the $)$ of type $<<\mathrm{e}, \mathrm{t}>, \mathrm{e}>$, making the whole DP to be of type $<\mathrm{e}>$ (mapping a predicate to an individual), each of which carries different information as to the familiarity of the NP referent, while Russian has an underspecified null D whose concrete interpretation is filled in each discourse situation by the C-I system.

In fact, Ramchand and Svenonius (2008: 228-29) propose that there is a principled distinction between the kinds of meaning that can be filled in by C-I and the syn/sem meanings. The former have to do with cross-sentential relations, general discourse coherence and are negotiable, but individual lexical items can provide information relevant to them. Table 1 exemplifies the various crosslinguistic options for mapping definiteness and specificity among Norwegian, English, Lillooet Salish and Russian (from Ramchand and Svenonius, 2008: 227), where 'syn/sem' stands for the meaning being fixed by the syntax while ' $\mathrm{C}-\mathrm{I}$ ' stands for the interpretation being resolved by the Conceptual-Intentional systems. ${ }^{4}, 5$ In this article, we are interested in the expression of definiteness.

Although Ramchand and Svenonius's (2008) proposal is highly speculative at this point and needs significant empirical augmentation, it bears important implications for language acquisition. If all languages have the same universal syntactic/semantic system and parametric variation lies in the way universal meanings are encoded (i.e. morphologically or contextually), one major difference between parameters is whether a parameter is overtly and directly (morphophonologically) marked with dedicated functional morphology, or covertly marked through various other linguistic means and/or context. The authors give an example from Norwegian and English specificity marking in child language (Anderssen, 2007), where Norwegian children may acquire specificity marking earlier than English children because of its overt expression. In a nutshell, overtness of morphemes may be related to faster acquisition.

\section{Assumptions and predictions}

We would like to make explicit our working assumption about features and their encoding, since the correct interpretations of our claims hinge on that understanding. Consistently with the vast literature on definiteness, we use the expression 'semantic feature' as a synonym of 'grammatical meaning encoded by languages of the world' (Alexiadou et al., 2007: 56; Lyons, 1999; among many others). Thus tense, progressive aspect and specificity would be other examples of semantic features beside definiteness. The feature [definite] represents a universal semantic-pragmatic concept (to be fleshed 
out below), but which is not uniformly realized across languages of the world, as some languages have articles and some do not. ${ }^{6}$

The next concept to elucidate is the concept of 'direct' and 'indirect' expression of features that we mentioned in the introduction. ${ }^{7}$ A feature is expressed directly if its meaning is the primary meaning of that expression. A feature is expressed indirectly if its meaning is not the primary meaning of its expression. Definite and indefinite articles expressing (in)definiteness is an example of a one-to-one form-meaning mapping, or a morphophonological expression of the feature [definite]; that is a direct mapping. All other determiners (quantifiers such as both, most; demonstratives such as this, these, etc.) have some primary meaning of their own, in addition to which they may encode one or another value of the feature [definite]; that would be indirect mapping of definiteness. Demonstrative pronouns, for example, are argued to be able to express [definite] by dint of their deictic [DEM] feature (Guisti, 2002). If we think about semantic features in this way, it is patently true that languages may have both direct and indirect ways to express the same feature. The feature [definite] is paired with a dedicated set of morphemes in English, and even if indirect ways of expressing definiteness exist, they are mostly redundant in contextualized utterances. Russian arguably has null counterparts of articles, or an underspecified D position whose value is supplied by D-linking context, lexical items and other means. In learning Russian, the indirect ways of marking the semantic feature necessarily take on added significance because the dedicated morphology is missing.

Another distinction between types of feature expressions is potentially useful and worth considering. Feature expressions can be 'overt', that is, expressed with dedicated functional morphology (e.g. [definite] and articles, [past] and -ed) or 'covert', i.e. entirely supplied by context or signaled by periphrastic means (e.g. the exact meaning of the English pronoun we discussed in the introduction, or Mandarin Chinese past tense signaled by adverbials such as yesterday, last week). We believe it is a reasonable prediction that the latter type of expression will be harder to acquire, for more or less the same reasons that indirect feature expressions are hard to acquire: inconsistent input. We would also classify word order changes, including scrambling to mark information structure, as covert grammatical expressions of a feature. Note that the latter is not exactly 'covertly' encoded, as the scrambled versus default word order can be detected (see Section V), but the encoding is much more unpredictable and difficult to track because different words are involved every time. To exemplify, scrambling to signal Topic is a direct and covert (in the sense of non-morphological) way of marking information structure; it could also be an indirect and covert way of marking definiteness.

In a nutshell, we suggest that dedicated functional morphology in a one-to-one relationship with a grammatical meaning is the most accessible, the clearest and the easiest to learn of all feature expressions. ${ }^{8}$ Adult learners looking for an equivalent of their L1 functional morpheme and not finding it will inevitably turn to covert and/or indirect ways for providing a feature value. However, context and word order changes are difficult to track, and lexical means of fixing a functional value vary from sentence to sentence and from situation to situation. In addition, the indirect means of coding the feature have other primary meanings of their own which may be easier to detect. Thus, there will 


\begin{tabular}{|c|c|c|c|c|c|}
\hline \multicolumn{4}{|c|}{ Easier to acquire } & \multicolumn{2}{|c|}{ Harder to acquire } \\
\hline$F_{\text {morpheme }}$ & $F_{\text {morpheme }}$ & $F_{\text {context }}$ & $F_{\text {morpheme }}$ & $\mathrm{F}_{\text {context }}$ & $\mathrm{F}_{\text {context }}$ \\
\hline $\begin{array}{l}\mathrm{F}_{\text {morpheme }} \\
\text { no re-assembly } \\
\text { required }\end{array}$ & $\begin{array}{l}\mathrm{F}_{\text {morpheme }} \\
\text { re-assembly } \\
\text { required }\end{array}$ & $\mathrm{F}_{\text {morpheme }}$ & $\mathrm{F}_{\text {context }}$ & $\begin{array}{l}\mathrm{F}_{\text {context }} \\
\text { no re-assembly } \\
\text { required }\end{array}$ & $\begin{array}{l}\mathrm{F}_{\text {context }} \\
\text { re-assembly } \\
\text { required }\end{array}$ \\
\hline
\end{tabular}

Figure I. Cline of difficulty in functional feature acquisition in various learning situations (adapted from Slabakova, 2009).

be no clear form-to-meaning mapping to be fixed in the learner's functional lexicon, hence the considerable learning difficulty.

Building on Ramchand and Svenonius's (2008) proposal, Lardiere's (2009) feature reassembly approach, and Slabakova's (2009) predictions dealing with overt and covert encoding of features, we propose that degrees of difficulty in feature acquisition can be represented as in Figure 1. $\mathrm{F}_{\text {morpheme }}$ stands for a functional feature that is encoded by dedicated morphophonological means, while $\mathrm{F}_{\text {context }}$ stands for a feature whose value is fixed by discourse tracking as well as some inconsistent (non-uniform) signals that require discourse observation, including word order changes. 'Feature reassembly' stands for figuring out different conditioning environments for the expressions of the grammatical meanings.

We offer this cline of difficulty in Figure 1 as an idealization that could rarely be exemplified with actual linguistic properties. To be sure, these are only two possible dimensions of difficulty that we have plotted in this cline: reassembly required or not, and overt versus covert feature encoding. Indirect encoding of a feature always brings on added difficulty. We believe that there are other factors implicating relative ease or difficulty of acquisition, for example, prosodic constraints on syllable structure, detectability of the feature exponent in the speech signal, one-to-one versus many-to-many exponents mapping, semantic complexity, etc. In the interest of more focused analysis and predictions, however, we will leave them aside for now. We will explain where the properties examined in this empirical study lie on this cline after we discuss the properties themselves.

\section{Definiteness marking in Russian, English and Korean}

\section{Overt and direct marking of definiteness in Russian: Possessor modifiers}

One of the many ways of marking definiteness in Russian is through the morphological form of the possessor-modifiers (Apresjan, 1995). The definite or indefinite interpretation of the possessor is expressed through its morphological form. Adjectival possessormodifiers (hereafter adjectival possessors) are interpreted as indefinite, as in (1), whereas postnominal genitive case-marked noun modifiers (hereafter nominal possessors) are underspecified for definiteness and can give either a definite or indefinite reading depending on context, as in (2). Consider examples from Apresjan (1995: 258) 
(1) Za dverju slyšalsja ženskij golos

behind door heard woman-ADJ.NOM

voice-NOUN.NOM

'A woman's voice was heard behind the door.'

(2) Za dverju slyšalsja golos ženščiny

behind door heard voice-NOUN.NOM woman-NOUN.GEN

'The voice of a/the woman was heard behind the door.'

In (1), the modifier denoting the possessor (ženskij 'woman-ADJ') is an adjectival form; thus, the possessor is interpreted as indefinite (any woman). The possessor in (2) (ženšciny 'woman-NOUN-GEN') is a noun form and the interpretation of the referent is ambiguous between any (indefinite) woman or an already-known, specific woman. As illustrated in the examples above, an indefinite interpretation of adjectival possessors is encoded overtly through the morphological form of the possessor. The underspecified [definite] interpretation of nominal possessors, on the other hand, can only be disambiguated by context.

A similar linguistic phenomenon is observed in Korean, that is, the indefinite or definite interpretation of the possessor can be encoded through its morphological characteristics. Nominal possessors without case are marked for indefiniteness, as in (3a), while genitive-marked nominal modifiers are unmarked, as in (3b). ${ }^{9}$

(3) a. yeoja moksori

woman-NOUN.NOM voice

'the voice of a woman'

b. yeoja-ui moksori

woman-NOUN.GEN voice

'the voice of a/the woman'

Notice two major differences between Korean and Russian regarding this phenomenon. First, in Russian, the interpretation of the possessor is encoded through its morphological form (adjectival versus nominal). In Korean, both types of possessors are nominal (the noun-noun compound construction; for various types of Korean compound nouns, see Kim et al., 2001) and the interpretation distinction comes from case marking (nominative versus genitive case). The second difference is that Korean does not allow postnominal modifiers; thus, any types of modifiers (regardless of their case) take the prenominal position in Korean, while nominal modifiers always take the postnominal position in Russian.

To recapitulate, one of the morphosyntactic ways to encode indefiniteness in Russian is through the morphological form of the possessor. Adjectival possessors are interpreted as indefinite, nominal possessors can be either definite or indefinite. Although this constitutes overt and direct marking by our own definition, the conditioning environment of this morphosyntactic phenomenon is rather complex, combining morphological marking and word order changes. It obviously does not hold for English, with some lexical exceptions. Such a distinction in modifiers does exist in 
Korean, another article-less language; thus, L1 transfer can be expected to be a factor in the acquisition of the possessor interpretation in L2 Russian by Korean speakers. However, as discussed above, the conditioning environments of marking the interpretation of possessors are not identical between Russian and Korean. This means that after establishing the initial mapping by detecting the similarities between the functional meanings of the target (Russian) and the L1 (Korean) linguistic phenomena, Korean speakers need to reassess the conditioning factors (i.e. case marking, the position and shape of modifiers) to complete the target feature [definite] set encoded through the types of possessor-modifiers.

\section{Covert and indirect marking of definiteness: Word order}

Word order has different functions cross-linguistically. In languages with impoverished morphology such as English, the main function of word order is to identify grammatical functions in a sentence; see examples in (4) and (5).

(4) The boy bit the dog.

(5) The dog bit the boy.

Grammatical functions of non-pronominal DPs can be identified only through word order as in (4) and (5); that is, subject precedes verb and object in the neutral word order.

In languages with rich morphology such as Russian, grammatical functions can always be identified morphologically by case, as demonstrated in examples in (6).

(6) a. Mal'čik ukusil sobaku.

boy-NOM bit dog-ACC

'The boy bit a/the dog.'

b. Mal'čika ukusila sobaka.

boy-ACC bit dog-NOM

'A dog bit the boy.'

In (6a) mal'čik 'boy-NOM' and sobak-u 'dog-ACC' indicate the subject and object, respectively. Note that the word order in (6a) is SVO, while it is OVS in (6b), that is to say, word order in Russian is not determined by grammatical functions. Word order permutations, however, are used to fulfill information structure requirements such as the marking of Topic and Focus. Related to that function, word order in Russian has the additional function of disambiguating 'articleless' bare DPs as to definite or indefinite interpretations. The information structure-definiteness connection is rather natural: Topics often contain information that is familiar to both the speaker and hearer, hence part of the common ground and definite, whereas focused constituents contain information that is new to the hearer, often indefinite. In neutral word order, Russian topics take the preverbal position, while focused DPs take the postverbal position. This is why preverbal DPs are generally given a definite interpretation (Chvany, 1973; King, 1995; Lambrecht, 2001; Rodionova, 2001), while postverbal DPs tend to receive an indefinite interpretation. Note 
that the underlying word order in Russian is generally assumed to be SVO (Bailyn, 2001; Hawkins, 1983; Tomlin, 1986). Consider examples from King (1995: 78).

(7) a. Na stole [+definite] stoja-la lampa [-def $]$.

on desk stand-Past lamp

'A lamp was on the desk / there was a lamp on the desk.'

b. Lampa [+definite] stoja-la na stole [-def].

lamp stand-Past on desk

'The lamp was on a/the desk.'

c. Na stole [+definite] lampa [+definite] STOJA-LA (a ne leža-la).

on desk lamp stand-Past (but not lie-Past)

'The lamp was standing on the desk (it was not lying).'

In (7a), the DP stole 'desk-LOC' in the preverbal PP na stole 'on the desk' gets a definite reading, while the post verbal DP lampa 'lamp' is interpreted as indefinite. In (7b), lampa 'lamp' is in the preverbal position and the PP na stole 'on desk' is in the postverbal position; thus, the former is definite and the latter is indefinite. In (7c), both stol 'desk' and lampa 'lamp' receive a definite reading since both are fronted to the preverbal position. However, as we will see below, even under stylistically neutral intonation, postverbal NPs can receive a definite reading.

Geist (2010) argues that the definite interpretation of bare singular DPs (i.e. underspecified DPs) can be determined rather freely from discourse if the referent is familiar to both the speaker and hearer. That is, a DP receives a definite interpretation regardless of its sentential position if the familiarity condition is met. Without the familiarity condition, a DP in the postverbal position is forced to receive an indefinite reading. Consider the following examples from Geist (2010: 194-95).

$\begin{array}{lllllllll}\text { (8) a. } & \text { Na tom stole } & \text { ležala } & \text { kniga } & \text { i } & \text { gazeta. } & \text { Anja } & \text { vzjala } & \text { knigu. } \\ & \text { on that table } & \text { lie } & \text { book } & \text { and } & \text { newspaper. Anja } & \text { took } & \text { book }\end{array}$

'A book and a newspaper were lying on that table. Ann took the book.'

b. Solntse vzošlo.

sun rose

'The sun rose.'

c. Odna/kakaja-to devočka vošla v dom.

one/some girl came into house

'A girl entered the house.'

In (8a) the referent kniga 'book' in the first sentence is in the postverbal position and there is no presupposition that the referent is familiar to the hearer as well as the speaker; hence, kniga 'book' receives an indefinite reading from being in the postverbal (Focus) 
Table 2. Correlation between word order and given-new status of the object in Russian, from Sirotinina (1965).

\begin{tabular}{lll}
\hline & Given object & New object \\
\hline VO & $166(39 \%)$ & $206(59.7 \%)$ \\
OV & $259(60.9 \%)$ & $139(40.3 \%)$ \\
\hline
\end{tabular}

position. The referent knigu 'book-ACC' in the second sentence is also postverbal; however, it is definite since the referent kniga 'book-NOM' was introduced in the previous discourse, which established familiarity. In (8b), the world knowledge that there is only one unique sun contributes to establishing familiarity and the reference solntse 'sun' receives a definite reading. Furthermore, indefinite DPs can be preverbal if overtly marked by quantifying adjectives as in $(8 \mathrm{c})$.

Corpus data confirm linguists' intuitions and the fact that there is just a tendency but not a 100\% correlation between word order and information structure in Russian. Sirotinina (1965), cited in Slioussar (2007), offers counts of VO and OV word orders in various Russian registers related to information structure. She reports $7-9 \%$ of preverbal objects in scientific speech, $10-12 \%$ in literary texts and up to $60 \%$ in colloquial speech. ${ }^{10}$ The counts in Table 2 show a rough division of $40 \%$ to $60 \%$ for the word order-information structure correlation.

Let us turn to the word order phenomenon in Korean. The canonical word order in Korean is SOV. Similar to Russian, the distribution of nominals in a sentence can encode (in)definiteness. However, differently from Russian, which allows virtually any word order, the Korean verb is always in the clause-final position; thus, no element can be in the postverbal position. Suh (2005) argues that in Korean, a Topic object DP [+definite] can scramble out of the verb phrase (VP) and land before the subject, resulting in OSV word order. As shown in (9b), scrambling of the object nominal gong 'ball' gives it a definite reading, while the nominal in situ (i.e. SOV) in (9a) has an indefinite interpretation (examples from Suh, 2005: 18).

(9) a. gak haksaeng-i gong-ul chat-da each student-NOM ball-ACC kick-PAST

'Each student kicked balls.'

b. gong-ul gak haksaeng-i chat-da

ball-ACC each student-NOM kick-PAST

'Each student kicked the ball.'

A rough generalization with respect to Korean word order is that fronted DPs get a definite interpretation, while DPs in situ are interpreted as indefinite. Thus, in principle, scrambling encoding topic-related definiteness can be transferred from the native Korean into the L2 Russian, provided the availability of SVO is acquired. However, differently from Russian, which allows virtually any word order, the Korean verb is always in the clause-final position; thus, no element can be in the postverbal position and both definite 
and indefinite nominals are in the preverbal position. The (in)definite interpretation of nominals in Russian is determined through the distribution of nominals in relation to the position of verb (preverbal versus postverbal), while in Korean the scrambled DP is in the sentence initial position. In other words, preverbal nominals are interpreted as definite in Russian, while preverbal nominals do not impose definiteness or topicality in Korean since all nominals as well as other elements are placed preverbally in Korean. Both $\mathrm{O}$ and $\mathrm{S}$ can be interpreted as definite in the OSV word order in Russian, while only $\mathrm{O}$ will be interpreted as definite in the OSV order in Korean.

In this subsection, we discussed how word order can disambiguate the (in)definite interpretation of bare underspecified DPs in Russian. Word order effects on definiteness in Russian are not as clear and categorically marked as English articles are, because the former are only indirect expressions of definiteness. A generalization such as 'preverbal DPs are definite and postverbal ones are indefinite' does not work $100 \%$ of the time. As we will see in Section VI, there are different degrees of acceptability/preference of the same word order even among native speakers. Such ambiguous and inconsistent input makes the acquisition process very complex and challenging.

\section{The learning tasks}

Definiteness is an overt category in English since it is predominantly marked through dedicated functional morphology. Thus, English speakers learning adjectival modifiers that encode indefiniteness have to remap their regular L1 morpheme (i.e. the indefinite article) onto quite a dissimilar L2 signal (two categories of modifiers). Although we would classify it as overt and direct, this remapping constitutes significant feature reassembly because of the different conditioning environments. Definiteness is primarily expressed through context in Korean, but it does have a similar distinction between anchoring and non-anchoring possessors, even though in a different position with respect to the verb and marked by case. So, when Korean speakers are faced with acquiring adjectival possessors, they can transfer the interpretive distinction but have to map their L1 overt feature expression onto the different feature expression in the L2. Although some reassembly is required in terms of position of the marking, it is possibly less reassembly than in the L2 English. We expect the Korean learners of Russian to be more accurate on this linguistic property than English learners of Russian.

Since definiteness can be expressed through word order in Russian, English speakers whose L1 marks the feature [definite] overtly have to reassemble their L1 morphemes (i.e. articles) into the covert and indirect way definiteness is expressed in the L2 (i.e. word order). Korean also expresses definiteness through word order; hence, the learning task for Korean speakers is to remap the covert and indirect way definiteness is encoded in their L1 onto another covert and indirect way the same feature is expressed in L2 Russian. However, as discussed in examples (11a) and (11b), the way Korean uses word order to signify definiteness differs from the way Russian alternates word order to encode definiteness. Both definite and indefinite DPs precede the verb in Korean, whereas the definite DP mostly precedes and the indefinite bare DP follows the verb in Russian. In other words, Korean has an OV structure that does not impose Topicality. English does not have OV at all. 
We expect that acquiring nominal interpretation signaled by word order permutations will be very difficult. In this respect, two diametrically opposed predictions can be made. One prediction would be that the intrinsic connection between information structure marking and definiteness in the native language would facilitate acquisition of the same connection in the second language. If this is correct, then Korean learners of Russian will be more accurate than English learners of Russian. If, on the other hand, English speakers establish a heuristic connection between word order and definiteness (aided by their native language morphological expression of the latter), they will be more accurate than Korean learners on the tested association (preverbal nominals are definite). In other words, English learners may mistakenly associate Russian word order permutations with definiteness rather than information structure. However, this association would give English speakers a clue to break into complex Russian indirect marking of definiteness, although it would not afford them the whole picture. We test these prediction in the experimental study described in Section VI.

\section{The experimental study}

\section{Participants}

The participants in this study included three language groups: a control group of native speakers of Russian $(n=56)$, L1 English group $(n=49)$, and L1 Korean group $(n=53)$. In order to control variables as much as possible, a couple of criteria were set for each group of participants. First, L2 learners' first exposure to Russian was after age 14, long after the critical period. Second, according to a number of studies (e.g. Sorace and Serratrice, 2009), discourse-dependent properties are more vulnerable to attrition. It is not the purpose of the present study to support or deny the claim; however, in order to rule out the possibility of attrition, native controls who had not lived in a foreign country were invited to take part in the experiment. Native participants were monolingual speakers of Russian, tested in Russia.

The participants were asked to provide demographic information such as gender, native language, and length of Russian study (for the learners). In addition, they also had to indicate their age group: (1) Age group I (18-30 years old), (2) Age group II (31-50), and (3) Age group III (over 50). Learners were tested in the USA, Moscow, and Seoul.

\section{Test instruments and procedure}

Two different tests were administered in this study: a proficiency test and a felicity judgment test, both conducted offline. At the beginning of the test, participants were given detailed instruction (in their native language). They could take as much time as they wanted to complete the tests. It took on average an hour to finish the tests, and participants were remunerated for their time and effort.

The proficiency test used in this study included 40 items and was adapted from the standardized Russian language test - also known as TRKI (Tipovoj test po russkomu jazyku kak inostrannomu) or TORFL (Test of Russian as a foreign language - for the level 3 (high advanced level) developed by the Ministry of Education of the Russian Federation. In this experiment, only the subtest for grammar and vocabulary was used. Forty items out of the 100 comprising this test were chosen, based on the level of difficulty. According to 
Table 3. Demographic characteristics and proficiency level of the participants.

\begin{tabular}{|c|c|c|c|c|}
\hline & Gender & Age group & $\begin{array}{l}\text { Years of } \\
\text { studying Russian }\end{array}$ & Proficiency test scores \\
\hline $\begin{array}{l}\text { Native speakers } \\
(n=56)\end{array}$ & $\begin{array}{l}27 \text { male } \\
29 \text { female }\end{array}$ & $\begin{array}{l}\text { I }(n=18) \\
\text { II }(n=34) \\
\text { III }(n=4)\end{array}$ & $\mathrm{n} / \mathrm{a}$ & $\mathrm{n} / \mathrm{a}$ \\
\hline $\begin{array}{l}\text { LI English } \\
(n=49)\end{array}$ & $\begin{array}{l}20 \text { male } \\
29 \text { female }\end{array}$ & $\begin{array}{l}\text { I }(n=29) \\
\text { II }(n=17) \\
\text { III }(n=3)\end{array}$ & $\begin{array}{l}\text { Range } 1-30 \\
(M=4.9)\end{array}$ & $\begin{array}{l}\text { Beginner }(n=10) \\
\text { Intermediate }(n=24) \\
\text { Advanced }(n=15)\end{array}$ \\
\hline $\begin{array}{l}\text { LI Korean } \\
(n=53)\end{array}$ & $\begin{array}{l}21 \text { male } \\
32 \text { female }\end{array}$ & $\begin{array}{l}\text { I }(n=33) \\
\text { II }(n=20)\end{array}$ & $\begin{array}{l}\text { Range } 1.5-19 \\
(M=4.05)\end{array}$ & $\begin{array}{l}\text { Beginner }(n=19) \\
\text { Intermediate }(n=15) \\
\text { Advanced }(n=19)\end{array}$ \\
\hline
\end{tabular}

Note: Age group I = I8-30 years old, Age group II = 3I-50, Age group III = over 50.

the TRKI's scoring criteria, those participants who answered more than $65 \%$ of the test items correctly were considered to be at the advanced level of proficiency in Russian. Three levels of proficiency (beginner, intermediate and advanced) were determined based on the proficiency test scores. Those who were correct on more than $65 \%$ of the test items $(65 \%$ of 40 items $=24)$ were placed in the advanced group. Learners who showed less than $40 \%$ of accuracy $(40 \%$ of $40=16)$ were placed in the beginner group. The rest, who scored between 16 and 24, were deemed to be intermediate learners. Korean and English groups were matched for proficiency. Additional $t$-tests were used to ensure two L1 groups of the same proficiency level were fully comparable. ${ }^{11}$ The demographic characteristics and proficiency level of the participants are summarized in Table 3.

The Felicity Judgment task (FJT, $k=64$ ), tested four properties, the two reported on in this article and two related to the marking of specificity (not reported on here). All the test items for the four different experimental conditions were combined into one felicity judgment task. By doing so, test items for one property served as filler items for the other properties $(12$ items $\times 4$ properties $=48)$ in addition to extra filler items $(k=16)$. Participants were asked to read short passages in their L1 (i.e. Russian, English or Korean) and rate the target sentences (all in Russian) as a felicitous or infelicitous description of the stories on a 5-point scale. Below are sample test items for the possessor modifier condition in (10) and (11). In the context of example (10), both sentences (10a) and (10b) should be accepted. In example (11), the sentence (11a) should be rejected as it cannot have a definite reading in the context of the story and sentence (11b) should be accepted.

(10) Contexts with an indefinite interpretation $(n=6)$

Sergei moved into a new apartment a couple of weeks ago. The apartment is in a great location and the rent is very good. Sergei is happy with the apartment but there's one problem. Sergei is having a hard time sleeping because some kids next door wake him up every night with their crying. Now Sergei is thinking about moving to another apartment.

a. Sergej bolše ne možet terpet' detsk-ij plač. [-definite]

Sergei longer not can tolerate child-ADJ.ACC crying-NOUN.ACC $\quad 1 \quad 2 \quad 3 \quad 34$

'Sergei can no longer tolerate some children crying.' I don't know 
b. Sergej bolše ne možet terpet' plač det-ej. [ \pm definite]

Sergei longer not can tolerate crying-NOUN.ACC child-NOUN. $\quad \begin{array}{llllll}\text { (5) } & 2 & 3 & 4\end{array}$ GEN.pl

'Sergei can no longer tolerate some/the children crying.'

I don't know

(11) Contexts with a definite interpretation $(n=6)$

Tatiana has three children. They wanted toys for Christmas. So, Tatiana took them to the biggest toy store in Moscow. When the kids could not find the toys they wanted at the store, all three kids started crying. Tatiana got upset and decided not to get them anything.

a. Tat'jana rasserdilas' iz-za detsk-ogo plač-a.

[-definite]

Tatiana got angry for child-ADJ.GEN crying-NOUN.GEN

(1) $2 \begin{array}{llll}2 & 3 & 4 & 5\end{array}$

'Tatiana got angry because of (some) children crying.'

I don't know

b. Tat'jana rasserdilas' iz-za plača detej.

[ \pm definite]

Tatiana got angry for crying-NOUN.GEN children-NOUN.GEN

$\begin{array}{llll}1 & 2 & 3 & 4\end{array}$

'Tatiana got angry because of the children crying.'

I don't know

Two contexts related to word order were tested in the task, one which presents the object of the test sentence as known (Topic, definite) and one which presents the object as unknown (Focus, indefinite). According to Kallestinova (2007), native speakers prefer the SVO order regardless of the definite or indefinite interpretation of the subject or object NP. The SVO is the neutral word order in Russian and native speakers can always ' fix' the definite or indefinite interpretation using their own intonation. To get around this likely problem, we did not use SVO sentences in the task. Instead, the target sentences all used the OVS word order, where the definite object should be acceptable in preverbal position while the indefinite bare object (without additional quantifiers) should be unacceptable in that position. See sample test items (12)-(13).

(12) [+definite ] / Topic object in preverbal position (OVS should be accepted) $(n=6)$

Oleg and his brothers Sergei and Aleksei always help their mom make dinner. Today they made mushroom soup, baked potatoes and beet salad. When their dad came home and tried the soup, he asked: kto svaril takoj' vkusnij' sup? ('Who made such delicious soup?')
a. Sup svaril Oleg.
$\begin{array}{lllll}1 & 2 & 3 & 4 & (5)\end{array}$
Soup boiled Oleg
b. Ego svaril Oleg. it boiled Oleg

(13) [-definite] / focused object in preverbal position (OVS should be rejected) $(n=6)$

I was watching TV when Aunt Galya called. She wanted to talk to Mom. I told her that Mom is busy cooking. Aunt Galya asked: Što gotovit tvoja mama? ('What is your mom cooking?')
a. Sup gotovit mama.
(1) $2 \quad 3 \quad 4 \quad 5$ soup cooks Mom.
b. Sup gotovit ona. soup cooks she.


In context (12), the question is about who made the soup; hence, the subject is focused and indefinite. The object sup 'soup' is mentioned and definite. Thus, the preferred word order is OVS and participants were expected to accept the target sentences. Note that both (12a) and (12b) have the OVS order, but (12a) has a lexical NP sup 'soup', while (12b) has a pronoun ego 'it'. In creating the test items for this condition, it was important to keep the test format the same, with two test sentences to be judged under each context. Therefore, we used pronouns instead of full DPs as a second test sentence to judge. We treated these sentences as additional fillers. In (13), the question has the object što 'what' as its focus and the subject mama 'mom' as its Topic; thus, the subject is definite and should be in the preverbal position, producing the SVO order. Since both target sentences - with a lexical NP in (13a) and with a pronoun in (13b) - are in the OVS order, they should be rejected.

\section{Results}

In this section we describe the data obtained from the experimental study in relation to the predictions formulated in the previous section. While raw scores are used for pairwise comparisons (comparison between categories, e.g. adjectival possessor versus nominal possessor in [+definite] contexts), the scores were converted to reflect accuracy for comparisons between properties (i.e. possessor-modifiers versus word order). Thus, the scores on adjectival possessors in [+definite] contexts are converted as follows. A raw rating of 1 is converted into 5, 2 into 4, 3 remains as 3, 4 into 2 and 5 into 1, where 1 stands for inaccurate (unexpected) performance and 5 stands for accurate performance, no matter whether rejection or acceptance of the test sentence. The experimental design has one between-participants factor (Group), with seven levels (Russian native speaker controls, L1 English beginner, L1 English intermediate, L1 English advanced, L1 Korean beginner, L1 Korean intermediate and L1 Korean advanced). Our general research question is whether L2 learners acquire the overtly marked property, possessor-modifiers, earlier than the covertly marked property, word order. Thus, the within-participants variable is Property (possessor-modifiers versus word order). A repeated-measures ANOVA revealed a significant main interaction between two variables: Group * Property $\left(F_{6,151}\right.$ $=9.809, p<.0001)$. We further examined each property separately using ANOVA (repeated-measures) for each group to see whether there is an interaction between the type of context (definite and indefinite) and the type of possessor (adjectival and nominal), and an interaction between the type of object (definite and indefinite) and word order (OVS). Additionally, $t$-tests were used on the mean rates of each group to find whether each group shows significant contrast between acceptable (felicitous) and unacceptable (infelicitous) sentences. In order to avoid the possibility of higher Type I error when doing multiple $t$-tests, we conducted each $t$-test independently.

a Adjectival and nominal possessors. As discussed in Section V, adjectival possessors give rise to an indefinite interpretation of the possessor, while nominal possessors can be either definite or indefinite. A repeated-measures ANOVA conducted for each group revealed that there is a significant interaction between the type of context and the type of possessor for all groups (English intermediate group: $F_{1,23}=33.969, p<.0001$; English advanced group: $F_{1,14}=48.721, p<.0001$; Korean intermediate group: $F_{1,14}=6.939$, 
Table 4. Form-meaning mapping of possessor-modifiers and definiteness.

\begin{tabular}{lll}
\hline & [+definite] & [-definite] \\
\hline Adjectival possessors & $\mathrm{x} \uparrow \longleftrightarrow$ & $\sqrt{ }$ \\
Nominal possessors & $\sqrt{ } \downarrow$ & $\sqrt{ }$ \\
\hline
\end{tabular}

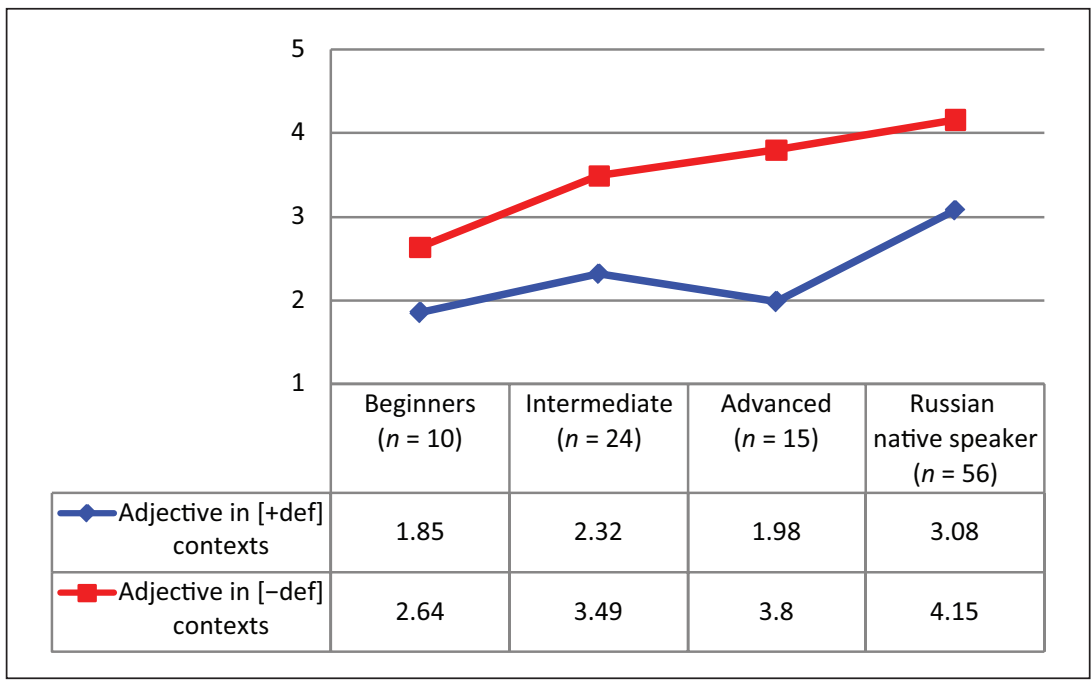

Figure 2. Mean ratings of adjectival possessors in different contexts, as in ( $10 \mathrm{a})$ versus ( $\mathrm{I} \mathrm{la})$ (LI English).

$p=.02$; Korean advanced group: $\left.F_{1,18}=44.449, p<.0001\right)$ except for the English beginner group $\left(F_{1,9}=2.328, p=.161\right)$ and the Korean beginner group $\left(F_{1,18}=4.175, p=.056\right.$, marginally significant). In order to detect more subtle effects, a series of $t$-tests were calculated between the mean rates of each possessor type in two different types of context. In order to demonstrate knowledge of this marking, participants should rate adjectival possessors low and nominal possessors high in definite contexts. Adjectival possessors should be more acceptable in indefinite than in definite contexts (see the red arrow in Table 4). However, another way of looking at the same contrast is possible: nominal possessors should be rated higher than adjectival possessors in [+definite] contexts; see the vertical arrow in Table 4. We will present both comparisons, one in Figures 2 and 3 and the other in Table 5.

When comparing knowledge of the contrasts in the two different directions (adjectival possessors in [+definite] versus [-definite] contexts, nominal versus adjectival possessors in definite contexts), the Korean groups at all proficiency levels display a significant knowledge in both contrasts, while the English groups do so for the second contrast only. Using independent samples $t$-tests, we directly compared the acceptability ratings of the different L1 groups at the same proficiency level. 


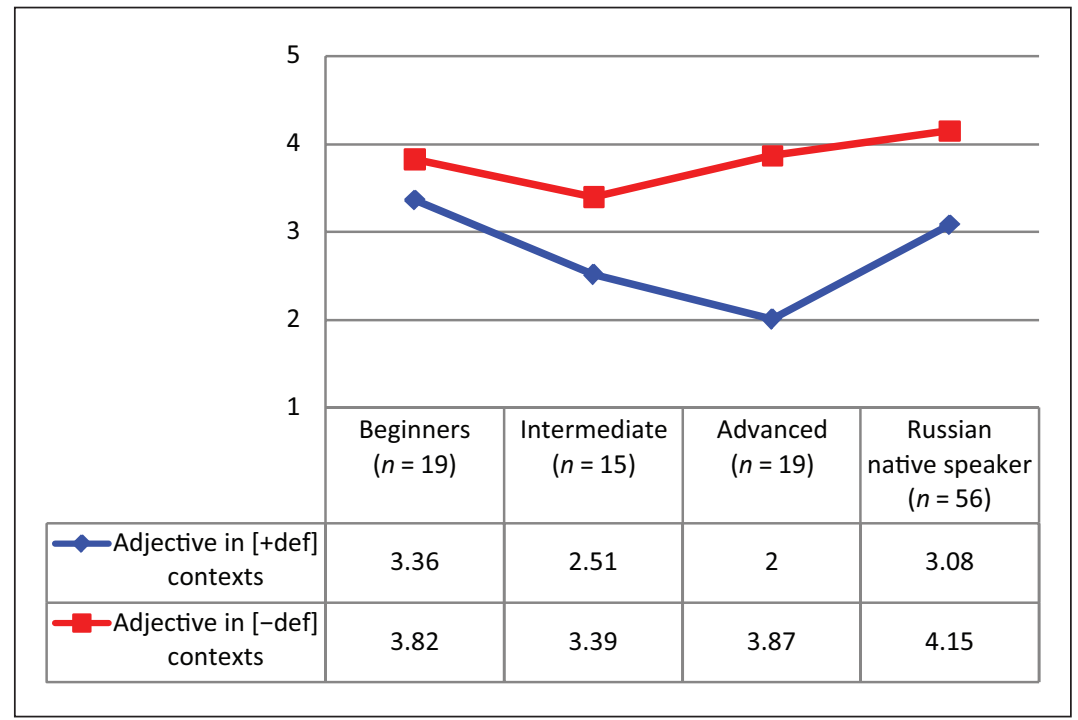

Figure 3. Mean ratings of adjectival possessors in different contexts, as in ( $10 \mathrm{a})$ versus ( $\mathrm{I} \mathrm{Ia})$ (LI Korean).

The Korean learners performed significantly better than the English learners at the beginning level in rating adjectival possessors in [ + definite] contexts $(t=-4.010, p<$ $.0001)$ and in [-definite] contexts $(t=-2.921, p=.007)$. The Korean groups and the English groups at the intermediate as well as at the advanced level did not differ from each other in all four conditions (adjectival possessors in [+definite] context; adjectival possessors in [-definite] context; nominal possessors in [+definite] context and nominal possessors in [-definite] context; for $t$ and $p$ values, see Table 13 in Appendix 1).

b Individual results on possessor-modifiers. Since we are looking at very subtle meanings, it was expected that group and individual results might diverge to some extent. The individual results were calculated as follows. If a participant gave a rating of the acceptable construction that was one scale unit higher than her rating of the unacceptable construction, we assumed that she had displayed sufficient knowledge of the contrast. For example, if a learner gave ' 2 ' to the adjectival possessors (unacceptable construction) and ' 3 ' to the nominal possessors (acceptable construction) in definite contexts, we accepted that the learner had demonstrated a contrast in her grammar between adjectival and nominal possessors. By this measure, not all native speakers were consistent with expectations. The results are summarized in Table 6.

c Word order expressing topic and definiteness. This subsection reports descriptive and statistical analyses of word order within each group to examine if the native speakers of Russian and the English- and Korean-speaking learners rate the OVS order differently when the object is presented by the context as definite and when the object is presented 
Table 5. Pairwise comparisons between adjectival and nominal possessors in two different contexts within each group $(\alpha=.05)$.

\begin{tabular}{|c|c|c|c|c|}
\hline & \multicolumn{2}{|c|}{$\begin{array}{l}\text { Contrast between adjectival } \\
\text { possessors in [-definite] } \\
\text { (IOa) versus [+definite] } \\
\text { (I la) contexts }\end{array}$} & \multicolumn{2}{|c|}{$\begin{array}{l}\text { Contrast within } \\
\text { [+definite] contexts: } \\
\text { adjectival possessors } \\
\text { (I la) versus nominal } \\
\text { possessors (I l b) }\end{array}$} \\
\hline & $t$ & $p$ & $t$ & $p$ \\
\hline $\begin{array}{l}\text { Russian native } \\
\text { speakers }\end{array}$ & -10.557 & $<.0001 *$ & 10.156 & $<.000 I^{*}$ \\
\hline English beginners & -1.976 & .08 (n.s.) & 8.019 & $<.000 I^{*}$ \\
\hline $\begin{array}{l}\text { English } \\
\text { intermediate }\end{array}$ & $-4.97 \mid$ & $<.0001 *$ & 10.007 & $<.000 I^{*}$ \\
\hline English advanced & -7.552 & $<.0001^{*}$ & 8.805 & $<.000 \mathrm{I}^{*}$ \\
\hline Korean beginners & -2.253 & $.037^{*}$ & 2.215 & $.04^{*}$ \\
\hline $\begin{array}{l}\text { Korean } \\
\text { intermediate }\end{array}$ & -3.055 & $.009 *$ & 5.963 & $<.000 I^{*}$ \\
\hline Korean advanced & -8.063 & $<.0001^{*}$ & 12.822 & $<.000 I^{*}$ \\
\hline
\end{tabular}

Note: $*$ stands for statistical significance at $p<.05$.

Table 6. Number and percentage of participants who showed a contrast between two conditions on possessor-modifiers.

\begin{tabular}{lll}
\hline & $\begin{array}{l}\text { Contrast between } \\
\text { adjectival possessors in } \\
\text { [-definite] }(\text { I Oa) versus } \\
\text { [+definite] contexts }(\mathrm{I} \mathrm{Ia})\end{array}$ & $\begin{array}{l}\text { Contrast within [+definite] } \\
\text { contexts: adjectival } \\
\text { possessors (I la) versus } \\
\text { nominal possessors (I Ib) }\end{array}$ \\
\hline Russian native speakers $(n=56)$ & $3 \mathrm{I}(55.36 \%)$ & $37(66.07 \%)$ \\
English beginners $(n=10)$ & $4(40.00 \%)$ & $10(100.00 \%)$ \\
English intermediate $(n=24)$ & $16(66.67 \%)$ & $21(87.50 \%)$ \\
English advanced $(n=15)$ & $14(93.33 \%)$ & $14(93.33 \%)$ \\
Korean beginners $(n=19)$ & $4(21.05 \%)$ & $1 \mathrm{I}(57.89 \%)$ \\
Korean intermediate $(n=15)$ & $10(66.67 \%)$ & $12(80.00 \%)$ \\
Korean advanced $(n=19)$ & $17(89.47 \%)$ & $18(94.73 \%)$ \\
\hline
\end{tabular}

as indefinite. Of course, these are the same situations where the object is Topic versus Focus. We consider the indirect relationship between definiteness and information structure in Section VII.

The Russian native speakers rated the OVS order with a definite object with an average 4.44 out of 5 , the same word order with an indefinite object with an average of 3.24. Figure 4 presents the mean ratings for the English learners and Figure 5 for the Korean learners.

Table 7 presents the intragroup comparisons between contextually acceptable and less acceptable fronted objects in OVS sentences. The English intermediate learners did not 


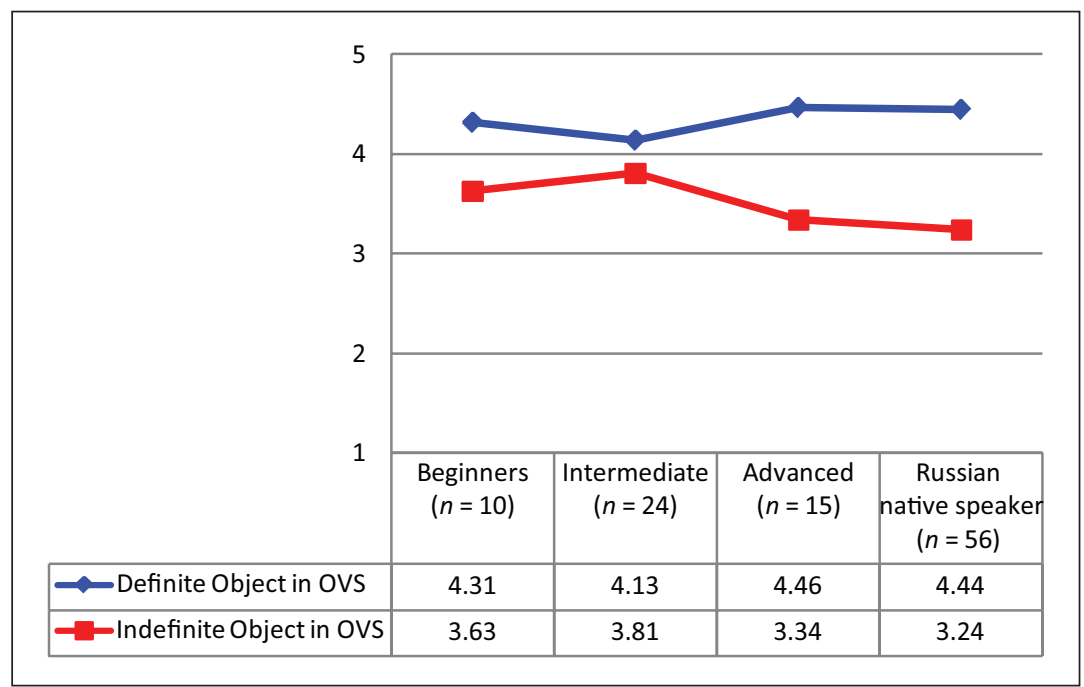

Figure 4. Mean rating of two types of objects in OVS word order as in (I2a) versus (I3a) (LI English).

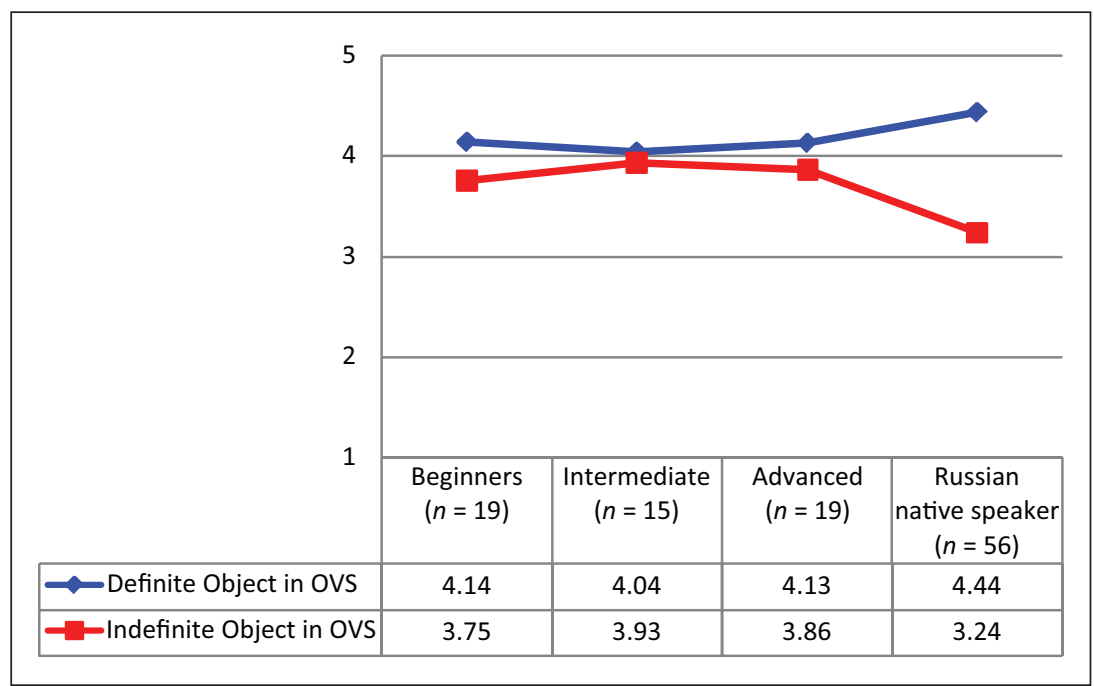

Figure 5. Mean rating of two types of objects in OVS word order as in (I2a) versus (I 3a) (LI Korean).

distinguish reliably between the two object interpretations, while the ratings of the beginning and advanced learners were significantly different. ${ }^{12}$ Korean-speaking learners performed rather homogenously in both conditions (definite object and indefinite object contexts) across all proficiency levels. Generally, they all rated the OVS sentences higher 
Table 7. The $[ \pm$ definite] interpretation of a preverbal object NP $(\alpha=.05)$.

OVS with definite object $>$ OVS with indefinite object $(12 a)$ versus (I3a)

\begin{tabular}{ll}
\hline Russian native speakers $(n=56)$ & $t=9.532, p<.000 I^{*}$ \\
English beginners $(n=10)$ & $t=2.570, p=.03^{*}$ \\
English intermediate $(n=24)$ & $t=1.927, p=.066$ (n.s.) \\
English advanced $(n=15)$ & $t=2.958, p=.0 I^{*}$ \\
Korean beginners $(n=19)$ & $t=1.941, p=.068$ (n.s.) \\
Korean intermediate $(n=15)$ & $t=.698, p=.496$ (n.s.) \\
Korean advanced $(n=19)$ & $t=1.707, p=.105$ (n.s.) \\
\hline
\end{tabular}

Table 8. Number and percentage of participants who showed a contrast of acceptability between the two types of sentences in the word order condition.

\begin{tabular}{ll}
\hline & $\begin{array}{l}\text { OVS with [+definite] object rated } \\
\text { higher than OVS with [-definite] object }\end{array}$ \\
\hline Russian native speakers $(n=56)$ & $33(58.93 \%)$ \\
English beginners $(n=10)$ & $4(40.00 \%)$ \\
English intermediate $(n=24)$ & $4(16.67 \%)$ \\
English advanced $(n=15)$ & $4(27.00 \%)$ \\
Korean beginners $(n=19)$ & $2(10.53 \%)$ \\
Korean intermediate $(n=15)$ & $1(6.67 \%)$ \\
Korean advanced $(n=19)$ & $2(10.53 \%)$ \\
\hline
\end{tabular}

in contexts with a definite object (as opposed to contexts with an indefinite object); however, the rate difference was not statistically significant. This suggests that Korean speakers of all proficiency levels did not make a distinction between the OVS with a definite object and the OVS with an indefinite object.

Independent samples $t$-tests revealed that the English and Korean learners of the same proficiency performed similarly in both the OVS word order with a definite object and the OVS word order with an indefinite object (for $t$ and $p$ values, see Table 14 in Appendix 1). However, looking closely at the individual data, we discovered a number of differences in performance between the English and Korean groups. We discuss the individual data in Section VII.

d Individual results on word order. Recall that the OVS word order is expected to be acceptable when the object has a definite interpretation, while it is supposed to be rejected when the object has an indefinite reading. We used the same procedure in evaluating the individual performance on this property, looking for a one unit or more of difference between raw mean scores, in the right direction. Table 8 presents the results.

Recall that the group results showed that the English and Korean groups performed similarly on word order. However, analyses of the individual data suggest otherwise. Take, for example, the advanced groups. Almost 30\% (4 individuals out of 15) of the advanced-level English learners exhibited the expected contrast, while only 2 
Table 9. Individual participant error patterns in the FJT on possessor-modifiers and word order.

\begin{tabular}{|c|c|c|c|c|}
\hline & \multicolumn{2}{|c|}{$\begin{array}{l}\text { Adjectival possessor- } \\
\text { modifiers }\end{array}$} & \multicolumn{2}{|l|}{ Word order (OVS) } \\
\hline & $\begin{array}{l}\text { Unexpected } \\
\text { acceptance } \\
\text { in [+definite] } \\
\text { contexts }\end{array}$ & $\begin{array}{l}\text { Unexpected } \\
\text { rejection in } \\
\text { [-definite] } \\
\text { contexts }\end{array}$ & $\begin{array}{l}\text { Unexpected } \\
\text { acceptance in } \\
\text { contexts with a } \\
\text { [-definite] object }\end{array}$ & $\begin{array}{l}\text { Unexpected } \\
\text { rejection in } \\
\text { contexts with a } \\
\text { [+definite] objects }\end{array}$ \\
\hline $\begin{array}{l}\text { Russian native } \\
\text { speakers }(n=56)\end{array}$ & 17 (30.00\%) & I5 (26.78\%) & $9(16.00 \%)$ & $2(3.57 \%)$ \\
\hline $\begin{array}{l}\text { English beginners } \\
(n=10)\end{array}$ & $0(0.00 \%)$ & $0(0.00 \%)$ & $5(50.00 \%)$ & $0(0.00 \%)$ \\
\hline $\begin{array}{l}\text { English intermediate } \\
(n=24)\end{array}$ & $2(8.33 \%)$ & I (4.16\%) & 12 (50.00\%) & $3(12.50 \%)$ \\
\hline $\begin{array}{l}\text { English advanced } \\
(n=15)\end{array}$ & I (6.67\%) & $2(13.33 \%)$ & 8 (53.33\%) & I (6.67\%) \\
\hline $\begin{array}{l}\text { Korean beginners } \\
(n=19)\end{array}$ & 3 (15.79\%) & 3 (15.79\%) & 8 (42.I I\%) & I (5.26\%) \\
\hline $\begin{array}{l}\text { Korean intermediate } \\
(n=15)\end{array}$ & $2(13.33 \%)$ & $3(20.00 \%)$ & $9(60.00 \%)$ & $0(0.00 \%)$ \\
\hline $\begin{array}{l}\text { Korean advanced } \\
(n=19)\end{array}$ & $0(0.00 \%)$ & $0(0.00 \%)$ & $2(10.52 \%)$ & $0(0.00 \%)$ \\
\hline
\end{tabular}

individuals, or about $10 \%$ of the advanced Korean learners, showed the contrast. This suggests that a larger number and percentage of English speakers have established the contrast in their grammar. The individual performance findings are also indicative of large individual differences among the Korean learners of the same proficiency level. We will address this issue in the discussion session.

In order to further investigate individual learners' error patterns, we next examined the individual data in another way. We classified a rating as incorrect if the participant rated OVS higher than 4 when the object was indefinite or rated it lower than 3 when the object was definite. We analysed the individual data on the possessor-modifiers in this way as well, so as to compare it with the word order individual results. The percentage of learners who showed one pattern or the other is shown in Table 9.

As shown in Table 9, learners' word order errors fall mostly into the pattern of 'incorrect acceptance', indicating that there is overgeneralization in the learners' grammars. With respect to the possessor-modifiers, we find similar percentages between the two patterns within each learner group. Note that some native speakers also exhibited the same patterns. These findings will be discussed in more detail in Section VII.

\section{Discussion}

We are now in a position to address the predictions formulated in Section IV based on the overt and covert encoding of features. As defined in Section IV, an overtly realized feature (or $\mathrm{F}_{\text {morpheme }}$ ) is a feature that is encoded by dedicated (consistent) morphological 
Table 10. Contrast within the learners' grammars.

\begin{tabular}{llll}
\hline & $\begin{array}{l}\text { Adjectival possessors } \\
\text { in [+definite] } \\
\text { contexts versus } \\
{[- \text { definite] contexts }}\end{array}$ & $\begin{array}{l}\text { Adjectival versus } \\
\text { nominal possessors } \\
\text { in [+definite] } \\
\text { contexts }\end{array}$ & $\begin{array}{l}\text { OVS word order with } \\
\text { [+definite] object } \\
\text { versus } \\
\text { [-definite] object }\end{array}$ \\
\hline $\begin{array}{l}\text { English beginners } \\
(n=10)\end{array}$ & no & yes & yes \\
$\begin{array}{l}\text { English intermediate } \\
(n=24)\end{array}$ & yes & yes & no \\
$\begin{array}{l}\text { English advanced } \\
(n=17)\end{array}$ & yes & yes & yes \\
$\begin{array}{l}\text { Korean beginners } \\
(n=19)\end{array}$ & yes & yes & no \\
$\begin{array}{l}\text { Korean intermediate } \\
(n=15)\end{array}$ & yes & yes & no \\
$\begin{array}{l}\text { Korean advanced } \\
(n=19)\end{array}$ & yes & yes & no \\
\hline
\end{tabular}

Notes. yes = significant rating difference between two conditions; no = no significant rating difference.

means, while a covertly encoded feature (or $\mathrm{F}_{\text {context }}$ ) is a feature whose value is supplied by context as well as by inconsistent (non-predictable) means that require discourse observation. We also defined indirect feature expression as not a primary but an additional meaning encoding. We would like to argue that these various means of feature expressions have an effect on learnability.

Based on Slabakova's (2009) predictions combined with Lardiere's (2009) feature reassembly model, we predicted that the English and Korean groups would perform similarly on possessor-modifiers since they face a somewhat similar learning task, that is, remapping the overtly realized [definite] feature in their L1 onto the overtly encoded [definite] feature with reassembly. However, we also noted that more reassembly was necessary in the English to Russian direction than in the Korean to Russian direction, as Korean formally distinguishes non-referential from regular possessors.

We also argued that acquisition of definiteness marking through word order, encoded indirectly and together with Topic marking in Russian, will be exceedingly difficult. We formulated two opposing predictions and left it as an empirical research question to see whether English or Korean learners would demonstrate superior accuracy.

The group performance findings are summarized in Table 10. As shown in the table, the Korean groups are more accurate than English learners in rating acceptability of adjectival possessors in definite and indefinite contexts, while both L1 groups are equally accurate in rating acceptability of adjectival and nominal possessors in definite contexts. In this respect, our prediction in Section V.3 that Korean learners would be more accurate than English learners is partially supported.

With respect to word order, the beginner and advanced English-speaking learners made a significant distinction between the OVS word order with a definite object and the OVS with an indefinite object (see Table 7 for $p$-values). The Korean speakers of all 
proficiency levels, however, did not demonstrate a significant difference in rating the OVS with a definite object and the OVS with an indefinite object. In this respect, the second of the two diametrically opposed predictions formulated in Section V.3 was supported. The Korean speakers' performance on word order (i.e. no successful acquisition detected even at the advanced group level) indicates that remapping a covertly realized feature (in both the L1 and L2) that requires reassembly presents the most challenging learning task. We speculate that the fact that Korean has an OV structure that does not impose Topicality was difficult to overcome by Korean learners of Russian.

On the other hand, English learners appear to be more successful in connecting Russian definiteness with word order. They probably use a heuristic association between preverbal nominals and definiteness, which would be correct in the case of familiar definites and novel indefinites. We note that the combination of features [familiar] and [definite] is more natural and frequent than the combination [novel] and [definite]; the latter might need additional pragmatic accommodation. ${ }^{13}$

One issue regarding the group results that we would like to discuss before moving to the individual results is the different developmental patterns of the English learners on the contrast between adjectival and nominal possessors and the contrast of adjectival possessors in two different contexts: definite and indefinite. As shown in Table 5, English learners made a distinction between adjectival and nominal possessors (in definite contexts) earlier (at the beginner level) than they did between adjectival possessors in definite contexts and adjectival possessors in indefinite contexts (at the intermediate level). Ženskiy golos ('woman.ADJ voice') can have two interpretations: (1) generic (female voice), and (2) specific (the voice of a woman). We speculate that L2 learners initially have to notice that there are two types of possessor modifiers in Russian and that they are somehow different. Learners at beginning stages of acquisition might not know that possessors can be in adjectival form (which is not the case either in English or Korean). Thus, learners might have interpreted adjectival possessors as regular adjectives by assigning them a generic interpretation. In other words, learners would initially interpret ženskiy golos 'woman's voice' as a nonspecific female voice (as opposed to a male voice) rather than the voice of a specific woman. This may be the reason why the beginninglevel English learners made a significant distinction between adjectival and nominal possessor-modifiers but not between adjectival possessors in [+definite] and in [-definite] contexts. Once learners' proficiency level increases with more exposure to input, they come to know that possessors can be in an adjectival form in Russian and the adjectival possessors are interpreted as indefinite. However, this is purely a speculation at this point, since the present experiment cannot tease apart whether learners interpreted adjectival possessors as generic (ženskiy 'female') or non-specific (ženskiy 'a woman's') when giving an indefinite interpretation to adjectival possessors. ${ }^{14}$

We now turn to the individual data. We analysed the individual data in two ways. First, we identified learners who made a distinction between acceptable and unacceptable constructions by one or more scale unit. These participants were considered to have sufficient knowledge of the contrast between the acceptable and unacceptable interpretations of the construction. Second, we examined error patterns by identifying learners who incorrectly accepted unacceptable constructions by giving them a rating of 4 or higher and learners who incorrectly rejected acceptable constructions by giving them a 
rating of 3 or lower. We will start with the analysis of the percentage of learners who show a contrast in their grammar. Considering the contrast between the adjectival possessors in [+definite] contexts and the adjectival possessors in [-definite] contexts, the group results showed that both the English and Korean speakers at the intermediate and advanced levels made a significant distinction. In line with the group results, the individual data show that over $60 \%$ of the intermediate and around $90 \%$ of the advanced learners have acquired the distinction. With respect to the contrast between the adjectival and nominal possessors in [+definite] contexts, the group results indicated that both the English and Korean speakers of all proficiency levels made the distinction. Individual data show that about $60 \%$ of the beginner-level, over $80 \%$ of the intermediate-level and over $90 \%$ of the advanced-level learners demonstrated knowledge of the contrast. This suggests that regarding possessor-modifiers, the individual performance does not substantially differ from the group performance.

Let us now look at the individual performance on word order. Recall that the group data indicate that the English-speaking learners at the advanced level made a significant distinction between the OVS with a definite object and the OVS with an indefinite object. However, the individual data indicate that only $29.41 \%$ of the advanced-level learners actually rated the contrast with a difference of one scale unit. We further examined the individual data to see if learners' errors show certain patterns. We divided errors into two types: incorrect acceptance and incorrect rejection. As shown in Table 9, regarding the possessor-modifiers, similar percentages were found of the two types of errors. However, in the evaluations of word order in context, most of the errors fell into the pattern of incorrect acceptance. Only a small percentage of learners (0-12.5\%) incorrectly rejected the OVS. In other words, learners accepted the OVS when the object was Focus/indefinite as well as when the object was Topic/definite. This suggests that learners must have overgeneralized the flexibility of the Russian word order and concluded that any word order is acceptable, regardless of the information structure/definiteness interpretation. In this way, they have uncoupled word order and definiteness. This overgeneralization must be due to the fact that word order is a covert (non-uniform) and indirect way of marking definiteness, so that the evidence that learners get from the input is misleading, or at least the pattern is difficult to notice. This is precisely why covertly marked features are harder to acquire than overtly marked ones. Another possible reason (mentioned above) for the English learners being more accurate than the Korean learners is that the former could use definiteness in their L1 as a heuristic: if a DP is definite in English, put it preverbally in Russian; if it is indefinite, put it postverbally. ${ }^{15}$

To continue this line of argumentation, we would like to compare the word order results of this experiment with Ionin et al.'s (2004) results. Clearly, the two studies are not directly comparable as the proficiency groups and the tests may not be completely parallel; still, the examination of the respective findings may be profitable. The study investigated knowledge of English definite and indefinite determiners by Russian and Korean learners, the same languages we employ in our study. They combined the ratings of intermediate and advanced learners to get one L1 Korean and one L1 Russian group. However, the Korean group contained more advanced learners than the Russian one (as measured by the standardized Michigan test of proficiency). The Korean group was highly accurate in their article choice (over 80\%), although they did exhibit the pattern 
of fluctuation (see Section II). The Russian group exhibited much more fluctuation, with error rates ranging up to $33-36 \%$. Sixteen out of 39 Korean speakers and 5 out of 26 Russian speakers had completely acquired the parameter setting (falling into the definiteness individual pattern). (In addition, 11 Koreans and 9 Russians showed the fluctuation pattern; for more details, see Ionin et al., 2004: 38-39). In contrast, none of the Korean groups in our test, and only 5 individual participants (less that 10\%) from all three levels of proficiency, were sensitive to the word order marking of definiteness. The comparison suggests that acquiring a meaning signaled by overt grammatical morphemes may be easier than acquiring the same meaning signaled by various contextual means. To be sure, since definiteness marking through word order and Topic/Focus marking are mostly conflated in Russian, this failure of acquisition could be explained by the Interface Hypothesis (Sorace and Serratrice, 2009). But article suppliance in general is context dependent, so this objection would be valid for both learning directions. Our larger point here is that if meanings are represented by non-morphological means, their acquisition will be hard, especially if these meanings are discourse sensitive.

Finally, let us address the definiteness-information structure confound in our experiment. While we acknowledge that it is a confound, it is very difficult to avoid. It is true that in our experimental design we test how learners interpret word order to encode Topicality, and the feature [definite] is secondary and dependent on that. It is also true, as we mentioned in Section V, that word order and Topicality are not 100\% aligned. However, the conditions under which novel definites can be preverbal and familiar indefinites can be postverbal are poorly understood in the literature on Russian. Information structure (Topic-marking) is the most often cited indirect means of attributing definiteness interpretation to arguments (Brun, 2001, among many others), that is why we decided to include this property in our experimental study testing the various ways of definiteness expression. Since Russian has little direct expression of definiteness (adjectival possessors), most other expressions of the feature will be indirect. If we want to investigate ways of marking definiteness without articles, we have to study indirect expressions that signal first something else, and additionally, definiteness. Although imperfect, our research design still affords us a comparison of definiteness expressions.

\section{Conclusions}

The goal of the present study was to examine the L2 acquisition of definiteness in Russian, a language without overt articles, focusing on the acquisition of two separate and unrelated expressions of definiteness (adjectival possessors and word order) by English and Korean speakers. In this study, we established the degrees of difficulty and developmental patterns based on three factors: whether reassembly is required or not (Lardiere, 2009), whether the feature is encoded overtly or covertly (Slabakova, 2009), and whether the expression of the feature is direct or indirect. Findings of the study appear to indicate that it is more challenging to acquire a feature when it is marked overtly in the L1 but covertly in the L2 than when a feature is marked with some functional morphology in both the L1 and L2. Moreover, the findings imply that the most challenging learning task is when a feature is encoded contextually and indirectly in both 
the L1 and L 2 but reassembly is required (the case of Korean speakers learning Russian word order that signals definiteness). These findings suggest that the indirect nature of feature expression, as well as the overt and covert feature encoding, should be added as significant factors when considering feature reassembly in L2 acquisition.

\section{Funding}

This research received no specific grant from any funding agency in the public, commercial, or not-for-profit sectors.

\section{Declaration of Conflicting Interest}

The author declares that there is no conflict of interest.

\section{Notes}

1. In this article, 'morpholexical item' refers to language-specific morphemes with functional features such as the, $-s$, -ed, as well as null morphemes. We retain 'lexical item' for idiosyncratic entries of the mental lexicon, but not the functional lexicon.

2. In particular, we adopt Ionin et al.'s (2004: 5) definition based on Heim (1991): 'If a Determiner Phrase (DP) of the form [D NP] is [+definite], then the speaker and hearer presuppose the existence of a unique individual in the set denoted by the NP.'

3. In personal communications, G. Rappaport and R. Sprouse have suggested to us that some languages may not express definiteness or specificity at all. If this is indeed the case, it could be a matter of underspecified versus fuzzy meaning, as discussed in semantics. In this article, however, we assume that definiteness and specificity are universal meanings; thus, all languages have to express these meanings in one way or another.

4. It seems to us that the Article Choice Parameter (Ionin, 2003) can be reformulated using this type of approach. However, such a reformulation is beyond the scope of the present work.

5. Table 1 is cited from Ramchand and Svenonius and, in our opinion, omits some feature expressions while trying to make a bigger point. For example, the table incorrectly asserts that Russian does not mark specificity overtly, while in fact Russian has a range of indefinite pronouns and determiners derived from them (koe-kakoj, kakoj-to, kakoj-nibud'), which do mark specificity and/or scope, and whose acquisition we investigate in other work.

6. We will not consider formal syntactic features in this article. The 'feature reassembly' that we will discuss has only to do with noticing and acquiring the different expressions of the same semantic feature, [definite]. Thus, for example, we are not interested in the formal features that allow Russian scrambling from SVO to OVS but in the acquisition of the fact that this scrambling is appropriate with a D-linked, given object and not appropriate with an object newly introduced in the discourse or focused.

7. We thank Tania Ionin and Bonnie Schwartz for discussing these issues with us at the various venues where we presented this work. The direct-indirect distinction in feature encoding was inspired by the comments of an anonymous reviewer, for which we are grateful.

8. Van Hout (2008) makes very similar claims for child language acquisition. She argues for morphological salience and semantic complexity affecting the acquisition of telicity and perfective aspect across Dutch, Italian and Polish as first languages.

9. To the best of our knowledge, there is no literature on the definiteness interpretation of the possessor in Korean. However, a number of Korean informants confirmed the interpretation of the possessor as analysed in this article. A Japanese native speaker informant claimed that the same phenomenon is observed in Japanese as well. 
10. We believe Sirotinina reports (S)VO versus (S)OV word orders, not the complete fronting of the object in OVS. Still, these findings suggest that Russian allows considerable scrambling for non-information structure reasons. Within a Functional Sentence Perspective approach, Sirotinina (1965) comments that the fronted object takes on added 'communicative importance' and is usually foregrounded.

11. Beginner groups $(t=-1.597, p=.109)$; intermediate groups $(t=-.599, p=.208)$; advanced groups $(t=1.545, p=.072)$.

12. The beginner-level English group showed a significant difference in their ratings of two conditions (OVS with a definite object NP and OVS with an indefinite object NP) while the intermediate group did not. Considering the small number of participants $(n=10)$, the outcome of the beginner group should be considered as a statistical error rather than the U-shaped learning pattern found in child L1 acquisition.

13. That is why a definite DP has been argued to require a referent that is familiar or somehow salient (Heim, 1982, 1983). An example of a novel or unmentioned definite would be Jason bought a Honda. The steering wheel was positioned oddly. See Frazier (2006) for analysis and experimental data on presupposition of uniqueness accommodation by native speakers of English.

14. We thank an anonymous reviewer for this comment.

15. We thank an anonymous reviewer for this suggestion.

\section{References}

Alexiadou A, Haegeman L, and Stavrou M (2007) Noun phrase in the generative perspective. Berlin: Mouton de Gruyter.

Anderssen M (2007) The acquisition of compositional definiteness in Norwegian. Papers from the Language Acquisition Workshop 34: 252-75. University of Tromsø.

Apresjan J (1995) Leksičeskaja semantika: Sinonimičeckie sredstva jazyka [Lexical semantics: Synonymic means of language]. Moscow: Vostochnaya literatura.

Bailyn J (2001) Inversion, dislocation and optionality in Russian. In: Junghanns U and Zybatow G (eds) Current issues in formal Slavic linguistics 3. Frankfurt/Main: Peter Lang, 280-93.

Brun D (2001) Information structure and the status of NP in Russian. Theoretical Linguistics 27: 109-35.

Chierchia G (1998) Reference to kinds across languages. Natural Language Semantics 6: 339-405.

Chomsky N (2004) Beyond explanatory adequacy. In: Belleti A (ed.) Structure and beyond: The cartography of syntactic structures. New York: Oxford University Press, 104-31.

Chvany C (1975) BE-sentences in Russian. Columbus, OH: Slavica.

Dekydtspotter L and Sprouse R (2001) Mental design and (second) language epistemology: Adjectival restrictions of $w h$-quantifiers and tense in English-French interlanguage. Second Language Research 17: 1-35.

Dekydtspotter L, Sprouse R, and Anderson B (1997) The interpretive interface in L2 acquisition: The process-result distinction in English-French interlanguage grammars. Language Acquisition 6: 297-332.

Frazier L (2006) The big fish in a small pond: Accommodation and the processing of novel definites. Unpublished invited paper for the OSU Presupposition Accommodation Workshop, Ohio State University, OH, USA.

Gabriele A and Martohardjono $\mathrm{G}$ (2005) Investigating the role of transfer in the L2 acquisition of aspect. Proceedings of GASLA, 7, 96-110.

Garcia Mayo M (2009) Article choice in L2 English by Spanish speakers. In: Garcia Mayo M and Hawkins R (eds) Second language acquisition of articles: Empirical findings and theoretical implications. Amsterdam: John Benjamins, 13-34. 
Geist L (2010) Bare singular NPs in argument positions: restrictions on indefiniteness. International Review of Pragmatics 2: 191-227.

Guisti G (2002) The functional structure of noun phrases: A bare phrase structure approach. In: Cinque G (ed.) Functional structure in DP and IP: The cartography of syntactic structures: Volume 1. Oxford: Oxford University Press, 54-90.

Goad H and White L (2004) Ultimate attainment of L2 inflections: Effects of L1 prosodic structure. EUROSLA Yearbook 4: 119-45.

Gürel A (2006) L2 acquisition of pragmatic and syntactic constraints in the use of overt and null subject pronouns. In: Slabakova R, Prévost P, and Montrul S (eds) Inquiries in linguistic development. Amsterdam: John Benjamins, 259-82.

Halle M and Marantz A (1993) Distributed morphology and the pieces of inflection. In: Hale K and Keyser J (eds) The view from Building 20. Cambridge, MA: MIT Press, 111-76.

Hawkins J (1983) Word order universals. New York: Academic Press.

Hawkins R and Hattori H (2006) Interpretation of multiple wh-questions by Japanese speakers: A missing uninterpretable account. Second Language Research 22: 269-301.

Heim I (1982) The semantics of definite and indefinite noun phrases. Unpublished doctoral dissertation, University of Massachusetts, Amherst, MA, USA.

Heim I (1983) File change semantics and the familiarity theory of definiteness. In: Bauerle R, Schwarze C, and Stechow AV (eds) Meaning, use, and the interpretation of language. Berlin, Germany: De Gruyter, 164-90.

Heim I (1991) Artikel and definitheit [Articles and definiteness]. In: Stechow AV and Wunderlich D (eds) Semantics: An international handbook of contemporary research. Berlin: De Gruyter, 487-535.

Huebner T (1983) A longitudinal analysis of the acquisition of English. Ann Arbor, MI: Karoma.

Ionin T, Ko H, and Wexler K (2004) Article semantics in L2 acquisition: the role of specificity. Language Acquisition 12: 3-69.

Jackendoff R (2002) Foundations of language. Oxford: Oxford University Press.

Kallestinova E (2007) Aspects of word order in Russian. Unpublished PhD Dissertation, University of Iowa, USA

Kim JH, Kwak BK, Lee S, Lee G, and Lee JH (2001) A corpus-based learning method of compound noun indexing rules for Korean. Information Retrieval, 4, 115-132.

King TH (1995) Configuring topic and focus in Russian. Stanford, CA: Rand Corporation Publication.

Lambrecht K (2001) When subjects behave like objects: An analysis of the meaning of S and O in sentence-focus constructions across languages. Studies in Language 24: 611-82.

Lardiere D (2008) Feature-assembly in second language acquisition. In: Liceras J, Goodluck H, and Zobl $\mathrm{H}$ (eds) The role of formal features in second language acquisition. New York: Lawrence Erlbaum, 107-40.

Lardiere D (2009) Some thoughts on the contrastive analysis of features in second language acquisition. Second Language Research 25: 173-227.

Lazard G (2001) On the grammaticalization of evidentiality. Journal of Pragmatics 33: 359-67.

Lyons C (1999) Definiteness. Cambridge: Cambridge University Press.

Marsden H (2009) Distributive quantifier scope in English-Japanese and Korean-Japanese interlanguage. Language Acquisition 16: 135-77.

Montrul S and Slabakova R (2003) Competence similarities between native and near-native speakers: An investigation of the preterit/imperfect contrast in Spanish. Studies in Second Language Acquisition 25: 351-98.

Ramchand G and Svenonius P (2008) Mapping a parochial lexicon onto a universal semantics. In: Biberauer M (ed.) Limits of syntactic variation. Amsterdam: John Benjamins, 219-45. 
Rodionova E (2001) Word order and information structure in Russian syntax. Unpublished MA thesis, University of North Dakota, ND, USA.

Sirotinina O (1965) Poryadok slov v russkom jazyke [Word order in Russian]. Saratov: Saratov University Press.

Slabakova R (2003) Semantic evidence for functional categories in interlanguage grammars. Second Language Research 19: 42-75.

Slabakova R (2008) Meaning in the second language. New York: Mouton de Gruyter.

Slabakova R (2009) Features or parameters: Which one makes SLA easier, and more interesting to study? Second Language Research 25: 313-24.

Slioussar N (2007) Grammar and information structure: A study with reference to Russian. Unpublished doctoral Dissertation, Utrecht Institute of Linguistics, Utrecht, The Netherlands.

Snape N (2009) Exploring Mandarin Chinese speakers' L2 article use. In: Snape N, Leung YI and Sharwood Smith M (eds) Representational deficits in SLA: Studies in honor of Roger Hawkins. Amsterdam: John Benjamins, 27-51.

Sorace A and Serratrice L (2009) Internal and external interfaces in bilingual language development: Beyond structural overlap. International Journal of Bilingualism 13: 195-210.

Suh E (2005) The nominal phrase in Korean: The role of D in a 'determiner-less' language. Toronto Working Papers in Linguistics 24: 10-19.

Thomas M (1989) The acquisition of English articles by first- and second-language learners. Applied Psycholinguistics 10: 335-55.

Tomlin R (1986) Basic word order: Functional principles. London: Croom Helm.

Trenkic D (2008) The representation of English articles in second language grammars: Determiners or adjectives? Bilingualism: Language and Cognition 11: 1-18.

Van Hout A (2008) Acquiring perfectivity and telicity in Dutch, Italian and Polish. Lingua 118: $1740-65$.

Zdorenko T and Paradis J (2008) The acquisition of articles in child second language English: Fluctuation, transfer or both? Second Language Research 24: 227-50.

\section{Appendix I}

Table I I. Possessor-modifiers: Mean scores and standard deviations.

\begin{tabular}{|c|c|c|c|c|c|c|c|c|}
\hline & \multicolumn{4}{|c|}{ [+definite] contexts } & \multicolumn{4}{|c|}{ [-definite] contexts } \\
\hline & \multicolumn{2}{|c|}{$\begin{array}{l}\text { Adjectival } \\
\text { modifiers } \\
\text { (reject) }\end{array}$} & \multicolumn{2}{|c|}{$\begin{array}{l}\text { Nominal } \\
\text { modifiers } \\
\text { (accept) }\end{array}$} & \multicolumn{2}{|c|}{$\begin{array}{l}\text { Adj. } \\
\text { modifiers } \\
\text { (accept) }\end{array}$} & \multicolumn{2}{|c|}{$\begin{array}{l}\text { Nominal } \\
\text { modifiers } \\
\text { (accept) }\end{array}$} \\
\hline & Mean & SD & Mean & SD & Mean & SD & Mean & SD \\
\hline Russian native speakers $(n=56)$ & 3.08 & .98 & 3.49 & .66 & 4.15 & .75 & 3.25 & .77 \\
\hline English beginners $(n=10)$ & 1.85 & .86 & 4.64 & .47 & 2.64 & 1.15 & 4.38 & .91 \\
\hline English intermediate $(n=24)$ & 2.32 & 1.12 & 4.87 & .3 & 3.49 & .91 & 4.36 & .72 \\
\hline English advanced $(n=15)$ & 1.98 & 0.91 & 4.87 & .34 & 3.8 & .94 & 3.96 & .62 \\
\hline Korean beginners $(n=19)$ & 3.36 & 1.02 & 4.25 & 1.07 & 3.82 & .96 & 4.14 & I.II \\
\hline Korean intermediate $(n=15)$ & 2.51 & 1.21 & 4.77 & .37 & 3.39 & .62 & 4.55 & .49 \\
\hline Korean advanced $(n=19)$ & 2.0 & .99 & 4.99 & .06 & 3.87 & 1.05 & 4.14 & .95 \\
\hline
\end{tabular}


Table 12. Word order: Mean scores and standard deviations.

\begin{tabular}{|c|c|c|c|c|}
\hline & \multicolumn{2}{|c|}{$\begin{array}{l}\text { [+definite] object: } \\
\text { OVS (accept) }\end{array}$} & \multicolumn{2}{|c|}{$\begin{array}{l}\text { [-definite] object: } \\
\text { OVS (reject) }\end{array}$} \\
\hline & Mean & SD & Mean & SD \\
\hline Russian native speakers $(n=56)$ & 4.44 & .67 & 3.24 & .75 \\
\hline English beginners $(n=10)$ & 4.31 & .78 & 3.63 & 1.16 \\
\hline English intermediate $(n=24)$ & 4.13 & .99 & 3.81 & 1.12 \\
\hline English advanced $(n=15)$ & 4.46 & .4 & 3.34 & 1.55 \\
\hline Korean beginners $(n=19)$ & 4.14 & .96 & 3.75 & .99 \\
\hline Korean intermediate $(n=15)$ & 4.04 & .56 & 3.93 & .64 \\
\hline Korean advanced $(n=19)$ & 4.13 & .65 & 3.86 & 1.04 \\
\hline
\end{tabular}

Table 13. Possessor-modifiers: Comparisons in acceptability ratings between two LI groups of the same proficiency level.

LI English versus $\quad t \quad p$
LI Korean

\begin{tabular}{llcc}
\hline Adjectival possessors in & Beginners & -4.01 & $<.000 I^{*}$ \\
[+definite] contexts & Intermediate & -.486 & .63 \\
& Advanced & .282 & .78 \\
Nominal possessors in & Beginners & 1.085 & .287 \\
[+definite] contexts & Intermediate & .974 & .337 \\
& Advanced & -1.424 & .164 \\
Adjectival possessors in & Beginners & -2.921 & $.007 *$ \\
[-definite] contexts & Intermediate & .363 & .718 \\
& Advanced & -.249 & .805 \\
Nominal possessors in & Beginners & .582 & .565 \\
[-definite] contexts & Intermediate & -.899 & .374 \\
& Advanced & .127 & .899 \\
\hline
\end{tabular}

Notes. Independent samples $t$-tests, $\alpha=.05$

Table 14. Word order: Comparisons in acceptability ratings between two LI groups of the same proficiency level.

\begin{tabular}{|c|c|c|c|}
\hline & $\begin{array}{l}\text { LI English versus } \\
\text { LI Korean }\end{array}$ & $t$ & $p$ \\
\hline \multirow[t]{3}{*}{ Indefinite objects in OVS } & Beginners & -.297 & .769 \\
\hline & Intermediate & -.402 & .69 \\
\hline & Advanced & -1.159 & .255 \\
\hline \multirow[t]{3}{*}{ Definite objects in OVS } & Beginners & .484 & .632 \\
\hline & Intermediate & .321 & .75 \\
\hline & Advanced & 1.699 & .099 \\
\hline
\end{tabular}

Notes. Independent samples $t$-tests, $\alpha=.05$ 